AFMRD from the association Association of Family Medicine of Family Medicine Residency Directors Residency Directors

Ann Fam Med 2021;19:375-376. https://doi.org/10.1370/afm.2722.

\section{HIGHLIGHTS OF THE INNOVATION SHOWCASE}

Innovation is essential to the growth of family medicine as a specialty and to maintaining excellence in training and patient care in a health care environment under constant change. ${ }^{1,2}$ However, many leaders in family medicine residency education feel hindered by the standardization necessary to assure the competence of an independent family physician. Thirty-two percent of departing program directors report a lack of ability to innovate in their residency programs. ${ }^{3}$ Despite some restrictions, within the confines of the accreditation and board certification requirements, some of the best innovation in our specialty has taken place within residency programs. ${ }^{1,2}$

For over 15 years, the American Academy of Family Physicians Residency Leadership Summit (formerly Program Directors Workshop (PDW) and Residency Program Solutions (RPS) Residency Education Symposium) has featured an Innovation Showcase. At this showcase, 10 presenters share, in a rapid-fire format, innovations they have implemented in their family medicine residency programs. In 2021 ten presentations were given virtually. We share a brief summary of 3 interventions here that were presented at the 2021 Innovation Showcase. We hope that these implemented ideas encourage other family medicine educators to innovate to maximize scholarly activity, improve resident and program coordinator wellness, and help residents find opportunities for growth and personal improvement.

\section{Scholarly Shark Tank (R.F., S.M.)}

The Pitch: Are you looking to build excitement around residency scholarly activity? Try a Scholarly Shark Tank! Inspired by a similar session at an STFM conference $^{4}$, we created a fun annual event—also based on the popular TV show-where faculty and residents pitch scholarly project ideas to attract "investment" from fellow residents and faculty. As a newer community-based family medicine residency, Scholarly Shark Tank has been instrumental in building enthusiasm and culture around scholarly activity. Additionally, involving the whole residency in project development generates helpful feedback to hone ideas while also increasing collaboration. It works well_-if not betterin a virtual format.

The Business Plan: Scholarly idea submissions are due 1-2 months prior to the event. We provide mentoring and vet all proposals to ensure appropriate content and scope for resident projects. Presenters have 5 minutes to pitch and answer questions. Both thoughtful engagement and levity are encouraged (Baby Shark song recommended, but not required). Successful teams meet within 1 month to discuss next steps and maintain momentum.

The Bottom Line: Scholarly Shark Tank has led to a quadrupling in the number of active residency scholarly projects over the past 2 years.

\section{Implementation of Program Coordinator Office Hours to Improve Resident (and Program Coordinator) Wellness (M.O.)}

Five years ago, when experiencing staff turnover in our residency program, I found myself struggling to be available for my residents. Being pulled in different directions with meetings, projects, and daily fire drills, I was frequently out of the office when they needed me. I created "Michelle Time" to provide consistent, dependable office hours for administrative support. Establishing structured availability was essential for their wellness as well as mine. This was one thing I could do: be present.

By creating 3 one-hour sessions each week, there was improvement in residents' spirits. I was prioritizing time with them to address their needs. The simple act of me sitting on my designated Michelle Time throne (some would call this a chair) and making myself available actually made people feel better.

Currently, I host Michelle Time virtually on recurring meeting links. Residents log on as needed when there are multiple people on at the same time, I place them in a waiting room and meet with them individually.

In addition to the usual open-door policy, it's important for GME Coordinators/Managers to prioritize creating a consistent presence, even just an hour a week, to further support residents during their education.

\section{Personalized Education Plan (A.D., B.P.)}

Historically, residents-in-difficulty were placed on a remediation plan in our residency program. Faculty argued these were designed to help residents overcome obstacles and succeed, but residents said they felt punitive and unrelated to their personal goals. To address these concerns and nurture a culture of continuous self-reflection and growth, we transitioned to universal Personalized Education Plans (PEPs). 
All residents are on a PEP from day one. Our intention was to de-stigmatize being "on a plan," because the reality is we are training physicians to be lifelong learners, who are continuously reflecting and identifying opportunities for growth. This is an essential skill, not something to be feared.

Inspired by Hahn et $\mathrm{al}_{1}^{5}$ we created a PEP that prompts residents to reflect on their personal goals in and after residency, opportunities for growth, and SMART goals to achieve success. The program may suggest goals as well if faculty identify an opportunity for growth, which has allowed us to delay, or even avoid, a remediation plan altogether.

Central to our success was resident buy-in. We formally launched the PEP by meeting with the residents, sharing our motivation and vision, and soliciting feedback. One of the residents named the document, so meetings with advisors could be "PEP talks."

Steven R. Brown, MD, FAAFP, Phoenix, AZ, Rachel Friedman, MD, Shannon McDermott, PbD, Santa Rosa, $C A_{\text {, }}$ Michelle Olivieri, BBA, Lawrence, Massacbusetts; Annie O. Dertbick, PbD, Bethany Picker, MD, Lewiston, Maine

\section{References}

1. Newton WP, Magill M, Biggs W, et al. Re-Envisioning family medicine residencies: the end in mind. J Am Board Fam Med. 2021;34(1): 246-248.

2. Carek PJ, Anim T, Conry C, et al. Residency training in family medicine: a history of innovation and program support. Fam Med. 2017; 49(4):275-281.

3. Fernald D, Hester CM, Brown SR. Why family medicine program directors leave their position. Fam Med. 2021;53(5):347-354.

4. Liaw W. Feed a discipline (with research questions): become shark bait. STFM blog. March 24, 2017. Accessed May 5, 2021. https://blog.stfm.org/2017/03/24/ feed-a-discipline-with-research-questions-become-shark-bait/

5. Hahn TW, Carlson J, Huffer P. Goal-oriented assessment of learning (GOAL): An individualized learning plan for residents. STFM Messenger. September 2017. Accessed Apr 22, 2021. https://www. stfm.org/publicationsresearch/publications/educationcolumns/2017/ september

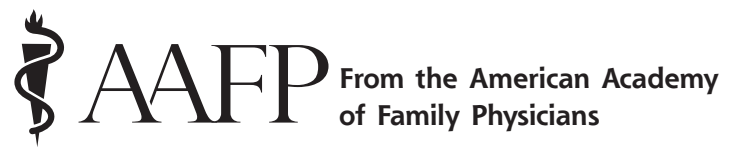

Ann Fam Med 2021;19:376-377. https://doi.org/10.1370/afm.2724.

\section{NASEM REPORT HERALDS PRIMARY CARE EVOLUTION, URGES ACTION}

A comprehensive report published in May by the National Academies of Sciences, Engineering and Medicine strengthens the case for primary care as the foundation of the US health care system. It also makes policy recommendations that reinforce several of the AAFP's long-standing advocacy positions.

"Primary care is the only health care component where an increased supply is associated with better population health and more equitable outcomes," concludes the 448-page Implementing High-Quality Primary Care: Rebuilding the Foundation of Health Care, which reflects some 18 months of research. The report is available at https://www.nap.edu/catalog/25983/ implementing-high-quality-primary-care-rebuildingthe-foundation-of-health.

The Academy was among the 17 co-sponsors of the study and will participate in stakeholder and lawmaker briefings accompanying its publication.

As a snapshot of how the authors define "better" and "more equitable" in the context of primary care, Americans, per capita, spend more than twice what citizens in Australia, France, Canada, New Zealand, and the United Kingdom pay for health care but experience worse health outcomes than people in those countries, the report notes. These nations, like the United States, are part of the Organization for Economic Cooperation and Development, whose members devote an average of $14 \%$ of all health care spending to primary care. In the United States, primary care visits account for $35 \%$ of health care visits yet make up only about $5 \%$ of health care expenditures.

The report echoes and extends a 1996 Institute of Medicine report, starting with an updated definition of high-quality primary care as the "provision of wholeperson, integrated, accessible and equitable health care by interprofessional teams who are accountable for addressing the majority of an individual's health and wellness needs across settings and through sustained relationships with patients, families and communities."

That earlier document, "Primary Care: America's Health in a New Era," (which the Academy also cosponsored), made a similar call to prioritize primary care. But it was less definite in establishing accountability methods for its proposals, which went largely 